\title{
Níveis de Energia Metabolizável para Frangos de Corte de 1 a 21 Dias de Idade Mantidos em Ambiente de Conforto Térmico
}

\author{
Jerri Teixeira Zanusso ${ }^{2}$, Rita Flávia Miranda de Oliveira $^{3}$, Juarez Lopes Donzele ${ }^{3}$, Rony Antonio \\ Ferreira $^{4}$, Horacio Santiago Rostagno ${ }^{3}$, Ricardo Frederico Euclydes ${ }^{3}$, Sandra Roselí Valerio ${ }^{4}$
}

\begin{abstract}
RESUMO - Este experimento foi realizado para avaliar níveis de energia metabolizável (EM) (2850, 2921, 3000,3075 e 3150 kcal/ $\mathrm{kg}$ ) para pintos de corte, machos, de 1 a 21 dias de idade, mantidos em ambiente de conforto térmico. Quatrocentos e cinquienta pintos, machos, com 44 $\pm 0,2 \mathrm{~g}$ de peso inicial médio, foram distribuídos em delineamento experimental inteiramente casualizado, com cinco tratamentos, nove repetições e dez aves por unidade experimental. O nível de EM da ração influenciou o ganho de peso médio diário e o consumo de energia metabolizável, que aumentaram, e a conversão alimentar, que reduziu linearmente com o aumento do nível de energia da ração. O nível de EM da ração influenciou as taxas de deposições de proteína e gordura na carcaça e o peso de gordura abdominal, que aumentaram linearmente, enquanto o rendimento de carcaça não foi influenciado. O nível de 3075 kcal EM na ração proporcionou o melhor desempenho das aves mantidas em condição de conforto térmico, na fase de 1 a 21 dias de idade.
\end{abstract}

Palavras-chave: ambiente de conforto, energia metabolizável, frangos de corte

\section{Metabolizable Energy Levels for Broilers (1 to 21 days) Maintained under a Thermoneutral Environment}

\begin{abstract}
This experiment was carried out to evaluate the metabolizable energy (ME) (2850, 2921, 3000,3075 e $3150 \mathrm{kcal} / \mathrm{kg}$ ) levels for male broilers from 1 to 21 days of age, maintained in thermoneutral environment. Four hundred and fifty chicks, male, with average initial $44 \pm 0.2 \mathrm{~g} \mathrm{LW}$, were allotted to a completely randomized experimental design with five treatments, nine replicates and ten animals per experimental unit. The ME level of the diet affected the average weight gain and the ME intake, which increased, and the feed:gain ratio, that linearly decreased with the increase of the dietary energy level. The dietary energy level affected the fat and protein deposition rates of the carcass and abdominal fat weight, which linearly increased, while the carcass yield was not affected. The dietary level of $3075 \mathrm{kcal}$ ME promoted the best broiler performance, from 1 to 21 days of age, maintained under a thermoneutral environment.
\end{abstract}

Key Words: thermoneutral, metabolizable energy, broiler

\section{Introdução}

As aves, como outros animais homeotérmicos, são influenciadas pelo ambiente. Assim, para qualquer alteração do ambiente, fora da faixa de conforto térmico, os animais necessitam de ajustes, sejam de natureza anatômica, fisiológica ou comportamental, na tentativa de se adaptarem à nova condição ambiental. $\mathrm{O}$ ambiente influencia o processo produtivo animal, principalmente, por alterar a troca de calor e o fracionamento da energia da ração, entre o ganho de energia e a dissipação de calor.

Dessa forma, proporcionar o conforto térmico para que as aves obtenham maior aproveitamento dos nutrientes da ração para o processo produtivo é meta principal a ser alcançada na avicultura moderna, uma vez que situações extremas de frio ou calor influenciam a produção dos frangos de corte, por modificar seu requerimento nutricional.

Segundo TARDIN (1995), a relação entre o balanço energético e o ambiente, sob o ponto de vista do conforto térmico das aves, é de extrema importância, considerando os aspectos produtivo e econômico.

As formulações das rações comerciais disponíveis, em geral, são feitas sem considerar, no entanto, as exigências nutricionais em razão da temperatura ambiente. Assim, em períodos em que a condição ambiental é desfavorável para o processo produtivo, esta ração será inadequada. Dessa forma, para maximizar o desempenho de um lote de aves, pode-se lançar mão de algumas estratégias que, na prática, se restringem a modificações ambientais ou à manipula-

\footnotetext{
${ }^{1}$ Parte da tese apresentada pelo primeiro autor à UFV. Projeto financiado pela FAPEMIG.

${ }^{2}$ Mestre em Zootecnia pela UFV.

3 Professor do DZO/UFV.

${ }^{4}$ Estudante de Doutorado do DZO/UFV.
} 
ção da ração, devendo-se sempre considerar, em ambos os casos, o aspecto econômico.

FABRÍCIO (1995) cita temperaturas do limite superior da zona de conforto térmico para algumas fases de desenvolvimento de frangos de corte, em que temperaturas de $31 ; 28 ; 26 ; 24 ; 23 ;$ e $21^{\circ} \mathrm{C}$ seriam os limites para as fases de 0 a $3 ; 4$ a $7 ; 8$ a $14 ; 15$ a 21; 22 a 30; e 31 dias até abate, respectivamente.

O presente trabalho foi conduzido com o objetivo de avaliar os efeitos de níveis de energia metabolizável (EM) sobre o desempenho e a composição de carcaça de frangos de corte de 1 a 21 dias de idade, mantidos em ambiente de conforto térmico.

\section{Material e Métodos}

O experimento foi conduzido em três câmaras climatizadas no Laboratório de Bioclimatologia Animal do Departamento de Zootecnia, do Centro de Ciências Agrárias da Universidade Federal de Viçosa, Viçosa, MG.

Foram utilizados 450 pintos de 1 dia de idade, machos, da linhagem Avian Farms, com peso inicial médio de 44+0,2 g, vacinados contra as doenças de Marek e Bouba aviária. Os animais permaneceram no experimento do $1^{\underline{o}}$ ao $21^{\circ} \underline{o}$ dia de idade.

As aves foram alojadas em grupos de 10 por compartimento, em baterias metálicas, com piso telado de área igual a $0,72 \mathrm{~m}^{2} /$ compartimento, dotadas de comedouros e bebedouros tipo calha, sendo cada compartimento uma unidade experimental. Cada bateria com 15 compartimentos foi colocada em uma câmara climática do Laboratório de Bioclimatologia Animal.

O programa de luz adotado durante todo o período experimental foi o contínuo (24 horas de luz artificial), fazendo-se uso de duas lâmpadas fluorescentes de $75 \mathrm{~W}$, cada, por sala.

Para a manutenção do conforto térmico das aves, seguiu-se a orientação do manual Avian Farms, com relação à combinação da temperatura ambiente e umidade relativa.

O monitoramento de temperatura e umidade de cada sala foi feito por meio dos termômetros de máxima e mínima, de bulbo seco e bulbo úmido e de globo negro, colocados à altura intermediária em relação ao compartimento central da bateria. As leituras dos termômetros foram realizadas diariamente, três vezes ao dia (8, 13 e $18 \mathrm{~h})$.

Na Tabela 1, são apresentados os valores médios de temperatura e umidade relativa do ar do interior das câmaras climáticas, assim como o valor médio do índice de temperatura de globo e umidade (ITGU).

As rações experimentais que constituíram os tratamentos (cinco níveis de energia metabolizável, Tabela 2) foram formuladas com níveis de proteína, minerais e vitaminas $5 \%$ acima do recomendado por ROSTAGNO et al. (1996). Os níveis de EM (2850, $2925,3000,3075$ e $3150 \mathrm{kcal} / \mathrm{kg}$ ) foram obtidos por meio de alterações nas proporções de óleo de soja refinado e inerte (CAULIN) nas rações. O critério de elevar o nível de proteína, minerais e vitaminas acima das recomendações foi adotado para garantir o atendimento das exigências nutricionais dos animais, devido à redução do fornecimento de ração, que correspondeu, em média, a 92,3\% do consumo voluntário.

Para determinação do consumo voluntário, utilizaram-se 50 aves distribuídas em grupos de 10 por bateria, mantidas em câmara climática, em condições de conforto térmico. Os animais receberam ração com $3000 \mathrm{kcal}$ de EM, correspondendo à exigência das aves no período, segundo ROSTAGNO et al. (1996).

As variáveis estudadas foram consumo de ração, ganho de peso, conversão alimentar, consumo de energia metabolizável, consumo de proteína bruta, rendimento de carcaça, taxa de deposição de proteína, taxa de deposição de gordura e peso de gordura abdominal.

O consumo foi calculado por diferença entre a quantidade de ração fornecida, os desperdícios e as sobras das rações experimentais, pesadas no início e no final do experimento. O fornecimento de água foi ad libitum, sendo trocada duas vezes ao dia.

Para determinação do ganho de peso, as aves foram pesadas no início e no final do experimento, ou seja, no período de 1 e 21 dias. A partir dos dados de consumo de ração e ganho de peso, calculou-se a conversão alimentar dos animais no período.

Ao final do experimento, após jejum de 6 horas, as aves foram pesadas, sendo escolhidas quatro de cada repetição, considerando-se o peso médio de cada unidade experimental (5\% acima e abaixo da média), e abatidas. Após serem sangradas, depenadas e evisceradas, as aves foram pesadas e a gordura abdominal foi retirada e pesada.

O rendimento de carcaça, expresso em percentagem, foi obtido pela razão entre o peso da carcaça (eviscerada, com pés e cabeça) e o peso após jejum.

As carcaças inteiras (incluindo pés e cabeça), sem as vísceras e o sangue, foram moídas, durante 15 minutos, em "cutter" comercial de 30 HP e 1775 rpm, 
1070 Rev. bras. zootec.

Tabela 1 - Temperatura, umidade relativa e índice de temperatura de globo e umidade (ITGU) observados durante a fase experimental

Table 1 - Temperature, relative humidity and black globe temperature index (HBGI) and humidity observed in the experiment

\begin{tabular}{lcccccc}
\hline $\begin{array}{l}\text { Idade }(\mathrm{d}) \\
\text { Age }\end{array}$ & $\begin{array}{c}\text { Temperatura } \\
\text { do ar }\left({ }^{\circ} \mathrm{C}\right) \\
\text { Air temp. }\end{array}$ & $\begin{array}{c}\text { Temperatura } \\
\text { máxima }\left({ }^{\circ} \mathrm{C}\right) \\
\text { Maximum temp. }\end{array}$ & $\begin{array}{c}\text { Temperatura } \\
\text { mínima }\left({ }^{\circ} \mathrm{C}\right) \\
\text { Minimum temp. }\end{array}$ & $\begin{array}{c}\text { Umidade relativa } \\
\text { Relative humidity }\end{array}$ & $\begin{array}{c}\text { Temperatura de } \\
\text { globo negro } \\
\text { Black globe temp. }\end{array}$ & $\begin{array}{c}\text { ITGU } \\
\text { HBGI }\end{array}$ \\
\hline 1 & $33,0 \pm 0,00$ & $33,0 \pm 0,00$ & $32,8 \pm 0,25$ & $47,0 \pm 3,00$ & $32,9 \pm 0,17$ & $82,7 \pm 0,27$ \\
2 & $31,5 \pm 0,00$ & $32,2 \pm 0,36$ & $31,3 \pm 0,66$ & $48,8 \pm 4,18$ & $31,9 \pm 0,46$ & $82,0 \pm 0,36$ \\
$3-4$ & $30,1 \pm 0,16$ & $30,7 \pm 0,62$ & $30,4 \pm 0,68$ & $53,5 \pm 4,44$ & $30,6 \pm 0,27$ & $80,5 \pm 0,38$ \\
$5-8$ & $28,7 \pm 0,00$ & $29,2 \pm 0,36$ & $28,8 \pm 0,44$ & $53,6 \pm 4,18$ & $29,0 \pm 0,14$ & $78,5 \pm 0,31$ \\
$9-11$ & $27,7 \pm 0,09$ & $28,1 \pm 0,32$ & $27,8 \pm 0,31$ & $56,8 \pm 1,78$ & $28,3 \pm 0,59$ & $77,6 \pm 0,53$ \\
$12-16$ & $26,3 \pm 0,74$ & $26,9 \pm 0,45$ & $26,7 \pm 0,42$ & $61,3 \pm 2,75$ & $27,1 \pm 0,51$ & $76,1 \pm 0,62$ \\
$17-21$ & $25,1 \pm 0,29$ & $26,2 \pm 0,49$ & $25,8 \pm 0,53$ & $66,1 \pm 4,63$ & $26,0 \pm 0,36$ & $75,0 \pm 0,50$ \\
\hline
\end{tabular}

${ }^{1}$ Valores médios (Average values).

obtendo-se amostra para posterior procedimento laboratorial.

As amostras de carcaça foram inicialmente présecadas em estufa com ventilação forçada a $\pm 60^{\circ} \mathrm{C}$, durante 72 horas. Posteriormente, em razão do alto teor de gordura, foi realizado pré-desengorduramento, pelo método a quente, em aparelho extrator do tipo "SOXHLET", durante 4 horas. Após esta etapa, as amostras foram moídas e acondicionadas em vidros, os quais foram armazenados para análises posteriores.

Os teores de água e gordura extraídos no processo de preparo das amostras foram considerados para a correção dos valores das análises. As análises de proteína e extrato etéreo das amostras foram realizadas no Laboratório de Nutrição Animal do Departamento de Zootecnia da UFV, conforme métodos descritos por SILVA (1990).

Um grupo adicional de 15 aves com 1 dia de idade foi abatido para determinação da composição corporal das aves no início do experimento. As deposições de proteína e gordura na carcaça foram calculadas pela diferença entre a composição da carcaça dos pintos de corte com 21 e 1 dia de idade.

Utilizou-se o delineamento experimental inteiramente casualizado, com cinco tratamentos (2850, 2950, 3000, 3075 e $3150 \mathrm{kcal}$ de EM/kg), nove repetições e dez aves por unidade experimental.

As análises estatísticas das características avaliadas foram realizadas utilizando-se o programa computacional SAEG (Sistema para Análises Estatísticas), desenvolvido pela UNIVERSIDADE FEDERAL DE VIÇOSA - UFV (1982). As estimativas de exigência de energia metabolizável foram estabelecidas por meio de modelos de regressão linear e quadrático, em níveis de 1 a 5\% de probabilidade.

\section{Resultados e Discussão}

Na Tabela 3 são apresentados os resultados de desempenho (ganho de peso, consumo de ração e conversão alimentar) e consumos de energia metabolizável e proteína bruta dos pintos de corte no período de 1 a 21 dias de idade, mantidos em ambiente de conforto térmico (recomendações Avian Farms) e alimentados com diferentes níveis de energia metabolizável (EM) na ração.

Foi verificado efeito $(\mathrm{P}<0,01)$ do nível de EM da ração sobre o ganho de peso (GP), que aumentou de forma linear (Tabela 4). Entretanto, observou-se que o maior valor absoluto de GP ocorreu no nível de $3075 \mathrm{kcal}$ de EM/kg.

Este resultado foi semelhante ao obtido por BERTECHINI et al. (1991) e BENÍCIO (1995), que também observaram aumento no GP de frangos de corte na fase inicial, em razão do aumento de EM da ração até o nível de $3200 \mathrm{kcal}$ de EM/kg. Entretanto, foi diferente do obtido por LEESON et al. (1996), os quais não constataram efeito do nível de energia da ração, que variou de 2700 a $3200 \mathrm{kcal}$ de EM/kg, sobre o ganho de peso de frangos de corte até os 25 dias de idade, mantidos em ambiente de conforto térmico.

Considerando que, com exceção da energia, os demais nutrientes atenderam às exigências das aves, pode-se inferir que o aumento linear do GP ocorreu em razão do incremento de consumo de energia metabolizável. Conseqüentemente, o aumento do ganho de peso observado neste trabalho pode estar relacionado à possível melhora gradativa da relação energia:proteína das rações. Com base nas recomendações de proteína e energia contidas no NUTRIENT... (1994), calcula-se que a relação energia:proteína das rações preconizadas para pintos de corte, na fase de 1 
ZANUSSO et al.

Tabela 2 - Composição centesimal das rações experimentais

Table 2 - Percentage composition of the experimental diets

Ingrediente $(\%)$

Ingredient

Nível de energia metabolizável (kcal EM/kg)

\begin{tabular}{|c|c|c|c|c|c|}
\hline \multirow[t]{2}{*}{ Ingredient } & \multicolumn{5}{|c|}{ Level metabolizable energy ( $\mathrm{kcal} \mathrm{ME} / \mathrm{kg})$} \\
\hline & 2850 & 2925 & 3000 & 3075 & 3150 \\
\hline Milho $(8,2 \% \mathrm{~PB})^{1}$ & 52,500 & 52,500 & 52,500 & 52,500 & 52,500 \\
\hline $\operatorname{Corn}(8.2 \% \mathrm{CP})$ & & & & & \\
\hline Farelo de soja $(47,6 \% \mathrm{~PB})^{1}$ & 37,230 & 37,230 & 37,230 & 37,230 & 37,230 \\
\hline Soybean meal $(47.6 \% C P)$ & & & & & \\
\hline Fosfato bicálcico & 1,966 & 1,966 & 1,966 & 1,966 & 1,966 \\
\hline Dicalcium phosphate & & & & & \\
\hline Calcário & 1,170 & 1,170 & 1,170 & 1,170 & 1,170 \\
\hline Limestone & & & & & \\
\hline Cloreto de colina & 0,084 & 0,084 & 0,084 & 0,084 & 0,084 \\
\hline Choline chloride & & & & & \\
\hline DL-metionina 99 & 0,245 & 0,245 & 0,245 & 0,245 & 0,245 \\
\hline DL-Methionine & & & & & \\
\hline Mistura vitamínica ${ }^{2}$ & 0,105 & 0,105 & 0,105 & 0,105 & 0,105 \\
\hline Premix vitamin & & & & & \\
\hline Mistura mineral $^{3}$ & 0,053 & 0,053 & 0,053 & 0,053 & 0,053 \\
\hline Premix mineral & & & & & \\
\hline Bacitracina de zinco & 0,020 & 0,020 & 0,020 & 0,020 & 0,020 \\
\hline Zinc Bacitracin & & & & & \\
\hline Coban $^{200}$ (anticoccidiano) & 0,060 & 0,060 & 0,060 & 0,060 & 0,060 \\
\hline BHT & 0,020 & 0,020 & 0,020 & 0,020 & 0,020 \\
\hline Sal & 0,415 & 0,415 & 0,415 & 0,415 & 0,415 \\
\hline Salt & & & & & \\
\hline Caulin & 3,925 & 3,071 & 2,218 & 1,364 & 0,511 \\
\hline Óleo de soja & 2,212 & 3,066 & 3,919 & 4,773 & 5,626 \\
\hline Soybean oil & & & & & \\
\hline
\end{tabular}

Composição calculada $^{4}$

Calculated composition

\begin{tabular}{|c|c|c|c|c|c|}
\hline \multirow{2}{*}{\multicolumn{6}{|c|}{$\begin{array}{l}\mathrm{EM}(\mathrm{kcal} / \mathrm{kg}) \\
M E\end{array}$}} \\
\hline & & & & & \\
\hline Proteína bruta (\%) & 22,19 & 22,19 & 22,19 & 22,19 & 22,19 \\
\hline \multicolumn{6}{|l|}{ Crude protein } \\
\hline $\mathrm{Na}(\%)$ & 0,210 & 0,210 & 0,210 & 0,210 & 0,210 \\
\hline $\mathrm{P}$ disponível (\%) & 0,478 & 0,478 & 0,478 & 0,478 & 0,478 \\
\hline \multicolumn{6}{|l|}{ Available P } \\
\hline $\mathrm{Ca}(\%)$ & 1,045 & 1,045 & 1,045 & 1,045 & 1,045 \\
\hline $\operatorname{Arginina}(\%)^{5}$ & 1,335 & 1,335 & 1,335 & 1,335 & 1,335 \\
\hline \multicolumn{6}{|l|}{ Arginine } \\
\hline $\operatorname{Lisina}(\%)^{5}$ & 1,189 & 1,189 & 1,189 & 1,189 & 1,189 \\
\hline $\begin{array}{l}\text { Lysine } \\
\text { Metionina + Cistina }(\%)^{5}\end{array}$ & 0,925 & 0,925 & 0,925 & 0,925 & 0,925 \\
\hline $\begin{array}{l}\text { Methionine }+ \text { Cystine } \\
\text { Metionina }(\%)^{5}\end{array}$ & 0,574 & 0,574 & 0,574 & 0,574 & 0,574 \\
\hline \multicolumn{6}{|l|}{ Methionine } \\
\hline Treonina $(\%)^{5}$ & 0,841 & 0,841 & 0,841 & 0,841 & 0,841 \\
\hline \multicolumn{6}{|l|}{ Threonine } \\
\hline Triptofano $(\%)^{5}$ & 0,291 & 0,291 & 0,291 & 0,291 & 0,291 \\
\hline Tryptophan & & & & & \\
\hline
\end{tabular}

${ }^{1}$ Valor obtido no Laboratório de Nutrição Animal do DZO/UFV, de acordo com metodologia descrita por SILVA (1990).

2 Conteúdo/kg (Content/kg): vit. A, 15.000.000 UI; vit. $D_{3}, 1.500 .000$ UI; vit. E, 15.000 Ul; vit. $B_{1}, 2,0$ g; vit. $\mathrm{B}_{2}, 4,0 \mathrm{~g} ;$ vit. $\mathrm{B}_{6}, 3,0 \mathrm{~g}$; vit. $\mathrm{B}_{12}, 0,015 \mathrm{~g}$, ácido nicotínico (nicotinic acid), $25 \mathrm{~g}$; ácido pantotênico (pantotenic acid), $10 \mathrm{~g}$; vit. $\mathrm{K}_{3}(3,0 \mathrm{~g}$ ); ácido fólico (folic acid), $1,0 \mathrm{~g}$; bacitracina de zinco (zinc bacitracin), $10 \mathrm{~g}$; Se (250 mg) e veículo q.s.p (inert), $1.050 \mathrm{~g}$.

${ }^{3}$ Conteúdo/kg (Content/kg): Mn, 60 g; Fe, 80 g; Zn, 50 g; Cu, 10 g; Co, 2,0 g; I, 1 g; e veículo q.s.p. (inert), $530 \mathrm{~g}$.

${ }^{4}$ Composição calculada segundo ROSTAGNO et al. (1996), com exceção da proteína bruta.

5 Composição em aminoácidos totais.

1 Value obtained according to the methodology described by SILVA (1990) - Animal Nutrition Lab, DZO/UFV.

${ }^{4}$ Composition calculated according to ROSTAGNO et al. (1996), except for crude protein.

${ }^{5}$ Composition total amino acids. 
1072 Rev. bras. zootec.

Tabela 3 - Desempenho e consumos de energia metabolizável (EM) e proteína bruta (PB) de frangos de corte de 1 a 21 dias de idade

Table 3 - Performance and metabolizable energy (ME) and crude protein (CP) intake of broilers from 1 to 21 days of age

\begin{tabular}{|c|c|c|c|c|c|c|}
\hline \multirow[t]{2}{*}{ Item } & \multicolumn{4}{|c|}{$\begin{array}{c}\text { Níveis de energia metabolizável (kcal EM/kg) } \\
\text { Metabolizable energy levels }(\mathrm{kcal} \mathrm{ME} / \mathrm{kg})\end{array}$} & \multirow[b]{2}{*}{3150} & \multirow[b]{2}{*}{$\mathrm{CV}(\%)$} \\
\hline & 2850 & 2925 & 3000 & 3075 & & \\
\hline$\overline{\text { Ganho de peso }(\mathrm{g})^{1}}$ & 519 & 533 & 534 & 566 & 553 & 3,62 \\
\hline $\begin{array}{l}\text { Weight gain } \\
\text { Consumo de ração }(\mathrm{g})^{2}\end{array}$ & 850 & 855 & 848 & 846 & 842 & 1,24 \\
\hline $\begin{array}{l}\text { Feed intake } \\
\text { Conversão alimentar }\end{array}$ & 1,64 & 1,60 & 1,59 & 1,50 & 1,52 & 3,15 \\
\hline $\begin{array}{l}\text { Feed:gain ratio } \\
\text { Consumo EM }(\mathrm{kcal} / \mathrm{kg})^{1} \\
\text { ME intake }\end{array}$ & 2423 & 2500 & 2544 & 2600 & 2653 & 1,28 \\
\hline $\begin{array}{l}\text { Consumo } \mathrm{PB}(\mathrm{g})^{2} \\
\text { CP intake }\end{array}$ & 189 & 190 & 188 & 188 & 187 & 1,24 \\
\hline $\begin{array}{l}\text { Relação energia:proteína } \\
\text { Energy:protein ratio }\end{array}$ & 12,84 & 13,18 & 13,52 & 13,86 & 14,20 & \\
\hline
\end{tabular}

a 21 dias de idade, seja de 13,9 e, segundo ROSTAGNO et al. (1996), igual a 14,2. Dessa forma, a relação observada no nível de $3075 \mathrm{kcal}$ de EM/kg, de 13,9, atendeu às recomendações contidas no NUTRIENT... (1994).

Os níveis de EM influenciaram a conversão alimentar (CA), que melhorou $(\mathrm{P}<0,01)$ de forma linear (Tabela 4), em razão do aumento do nível de EM da ração. De forma similar ao GP, o melhor valor absoluto de CA foi verificado no nível de $3075 \mathrm{kcal} \mathrm{de} \mathrm{EM/kg}$.

Efeitos positivos do aumento do nível de EM da ração sobre a CA de frangos de corte, na fase inicial de crescimento, também foram observados por BERTECHINI et al. (1991), HOLSHEIMER e RUENSKI (1993) e BENÍCIO (1995).

O consumo de EM também foi influenciado $(\mathrm{P}<0,01)$ pelos níveis de EM da ração, aumentando de forma linear (Tabela 4). O fato de o consumo de ração ter variado somente em $13 \mathrm{~g}$ entre os tratamentos explica este resultado.

Embora a variação de somente três gramas no consumo de proteína bruta tenha sido significativa $(\mathrm{P}<0,05)$, biologicamente não é suficiente para justificar as variações observadas no ganho de peso e na conversão alimentar das aves.

Os resultados de rendimento de carcaça e taxas de deposição de proteína e gordura na carcaça e de gordura abdominal são apresentados na Tabela 5 . Não se observou efeito dos níveis de EM da ração sobre o rendimento de carcaça dos animais. Este resultado foi similar ao obtido por Trindade et al. (1980) e Mendes et al. (1985), citados por
BERTECHINI et al. (1991), que não observaram efeito do nível da EM sobre o rendimento de carcaça das aves. Por outro lado, DALE e FULLER (1980) observaram aumento do rendimento da carcaça das aves, em razão da elevação do nível de EM da ração.

Os níveis de EM influenciaram $(\mathrm{P}<0,01)$ as deposições de proteína (DPC) e gordura (DGC) na carcaça, que aumentaram de forma linear (Tabela 4). O aumento observado na deposição de proteína estaria refletindo melhora gradativa na relação energia:proteína da ração, que nos níveis mais baixos pareceu insuficiente para garantir esta deposição no potencial do animal, uma vez que o consumo de proteína não variou entre os tratamentos, o que comprometeu o ganho de peso das aves. Com relação ao aumento da deposição de gordura, constatou-se que, apesar de ter aumentado de forma linear, a razão da deposição proteína:gordura na carcaça praticamente não alterou, variando de 53,3 $(2850 \mathrm{kcal})$ a $55,8 \%(3150 \mathrm{kcal})$. Estes resultados corroboram os obtidos por HOLSHEIMER e RUENSKI (1993), que verificaram aumento nas taxas de deposição de proteína e gordura na carcaça de frangos de corte aos 14 dias de idade, quando o nível de EM da ração aumentou de 2750 para $3250 \mathrm{kcal} \mathrm{EM} / \mathrm{kg}$. No entanto, BERTECHINI et al. (1991) e SIZEMORE e SIEGEL (1993) não observaram variação na DPC na carcaça de frangos de corte, em razão do aumento do nível de energias das rações.

Constatou-se que os níveis de energia influenciaram o ganho de peso e sua composição e o aumento da DPC se constituiu em fator que contribuiu para a melhora da CA. 
Tabela 4 - Regressão de diferentes variáveis sobre o nível de energia metabolizável (EM) da ração

Table 4 - Regression of different variables on dietary metabolizable energy (EM) levels

\begin{tabular}{|c|c|c|}
\hline Variável & Regressão & \\
\hline Variable & Regression & \\
\hline Ganho de peso (GP) & $G \hat{P}=141,808+0,13316 \mathrm{EM}$ & $\mathrm{r}^{2}=0,75$ \\
\hline Weight gain $(W G)$ & & \\
\hline Conversão alimentar (CA) & $C \hat{A}=2,9152-0,000447 \mathrm{EM}$ & $r^{2}=0,83$ \\
\hline Feed:gain ratio $(F G)$ & & \\
\hline $\begin{array}{l}\text { Consumo de EM (CEM) } \\
\text { ME intake (IME) }\end{array}$ & $C \hat{E} M=302,557+0,747209 \mathrm{EM}$ & $\mathrm{r}^{2}=0,99$ \\
\hline Deposição proteína carcaça (DPC) & $D \hat{P} C=7,129+0,02064 \mathrm{EM}$ & $\mathrm{r}^{2}=0,95$ \\
\hline $\begin{array}{l}\text { Carcass protein deposition (CPR) } \\
\text { Deposição gordura carcaça (DGC) }\end{array}$ & $D \hat{G} C=-20,3308+0,01944 \mathrm{EM}$ & $\mathrm{r}^{2}=0,95$ \\
\hline $\begin{array}{l}\text { Carcass fat deposition (DFC) } \\
\text { Gordura abdominal (GA) } \\
\text { Abdominal fat }(F A)\end{array}$ & $G \hat{A}=-5,4389+0,00322 \mathrm{EM}$ & $r^{2}=0,57$ \\
\hline
\end{tabular}

$\mathrm{EM}(M E)$

Tabela 5 - Rendimento de carcaça, deposição de proteína e gordura na carcaça e peso da gordura abdominal de frangos de corte de 1 a 21 dias de idade

Table 5 - Carcass yield, protein and fat deposition and abdominal fat weight of broilers from 1 to 21 days of age

\begin{tabular}{|c|c|c|c|c|c|c|}
\hline \multirow[t]{2}{*}{ Item } & \multicolumn{5}{|c|}{$\begin{array}{c}\text { Níveis de energia metabolizável }(\mathrm{kcal} \mathrm{EM} / \mathrm{kg}) \\
\text { Metabolizable energy levels }(\mathrm{kcal} \text { ME/kg) }\end{array}$} & \multirow[b]{2}{*}{$\mathrm{CV}(\%)$} \\
\hline & 2850 & 2925 & 3000 & 3075 & 3150 & \\
\hline Peso final (g) & 595 & 605 & 608 & 631 & 629 & 2,92 \\
\hline Final weight & & & & & & \\
\hline $\begin{array}{l}\text { Rendimento de carcaça }(\%) \\
\text { Carcass yield }\end{array}$ & 75,62 & 75,39 & 75,24 & 75,85 & 75,31 & 0,88 \\
\hline $\begin{array}{l}\text { Deposição de proteína na carcaça }(\mathrm{g})^{1} \\
\text { Protein deposition on carcass }\end{array}$ & 66,46 & 67,44 & 68,32 & 70,40 & 72,72 & 7,58 \\
\hline $\begin{array}{l}\text { Deposição de gordura na carcaça }(\mathrm{g})^{1} \\
\text { Fat deposition on carcass }\end{array}$ & 35,42 & 36,02 & 37,72 & 40,21 & 40,61 & 12,21 \\
\hline $\begin{array}{l}\text { Gordura abdominal }(\mathrm{g})^{1} \\
\text { Abdominal fat }\end{array}$ & 3,72 & 3,76 & 4,37 & 4,95 & 4,33 & 17,27 \\
\hline $\begin{array}{l}\text { Peso médio das aves em jejum }(\mathrm{g}) \\
\text { Fasting weight of birds }\end{array}$ & 572 & 576 & 581 & 601 & 602 & \\
\hline
\end{tabular}

${ }^{1}$ Efeito linear $(P<0,01)$.

Linear effect $(P<.01)$.

Com relação à gordura abdominal, verificou-se aumento $(\mathrm{P}<0,01)$ linear em razão do nível de EM da ração (Tabela 4). Apesar da variação linear crescente, constatou-se que no nível de $3150 \mathrm{kcal}$ de EM/kg a quantidade de gordura abdominal, em valor absoluto, correspondeu a $87,47 \%$ da observada no nível de $3075 \mathrm{kcal}$ de EM/kg. Efeito semelhante dos níveis de EM da ração (2700 a $3300 \mathrm{kcal}$ de $\mathrm{EM} / \mathrm{kg}$ ) sobre a gordura abdominal de frangos de corte mantidos em ambiente de conforto térmico foi também observado por LEESON et al. (1996).

Os resultados obtidos evidenciaram que o nível de EM da ração aumentou tanto a taxa de deposição de gordura na carcaça quanto a quantidade de gordura abdominal.

\section{Conclusões}

Embora tenha se observado melhora linear no ganho de peso e na conversão alimentar, concluiu-se que o nível de 3075 kcal de energia metabolizável na ração, correspondente à relação energia:proteína de 13,9 , proporcionou os melhores resultados para frangos de corte, machos, na fase de 1 a 21 dias de idade, mantidos em condição de conforto térmico.

\section{Referências Bibliográficas}

BENICIO, L.A.S. Estudo da influência de linhagens e de níveis nutricionais sobre o desempenho, rendimento de carcaça e avaliação econômica em frangos de corte. Viçosa, MG: UFV, 1995. 159 p. Tese (Doutorado em Nutrição de Monogástricos) 
1074 Rev. bras. zootec.

- Universidade Federal de Viçosa, 1995.

BERTECHINI, A.G., ROSTAGNO, H.S., SOARES, P.R. et al. 1991. Efeitos de programas de alimentação e níveis de energia da ração sobre o desempenho e a carcaça de frangos de corte. R. Soc. Bras. Zootec., 20:267-280.

DALE, N.M., FULLER, H.L. 1980. Effect of diet composition on feed intake and growth of chicks under heat stress. II. Constant vs. cycling temperatures. Poult. Sci., 59:1434-1441.

DANFOTH JR., E., BURGER, A.G. 1989. The impact of nutrition on thyroid hormone physiology and action. Ann. Rev. Nutr., 9:201-227.

FABRICIO, J.R. Influência do estresse calórico no rendimento da criação de frangos de corte. In: CONFERÊNCIA APINCO DE CIÊNCIA E TECNOLOGIA AVÍCOLAS, 1994, São Paulo. Anais... Santos, SP: FACTA, 1994, p.129-136.

HOLSHEIMER, J.P., RUENSKI, E.W. 1993. Effect on performance, carcass composition, yield, and financial return of dietary energy and lysine levels in starter and finisher diets fed to broilers. Poult. Sci., 72:806-815.

LEESON, S., CASTON, L., SUMMERS, J.D. 1996. Broiler response to diet energy. Poult. Sci., 75:529-535.

NUTRIENT REQUERIMENT OF POULTRY. 1994. 9.ed. Washington, D.C: NRC. $155 \mathrm{p}$.

OLIVEIRA, R.F.M. Efeito do nível de energia digestível e da temperatura ambiente sobre o desempenho e sobre os parâmetros fisiológicos e hormonal de suínos dos 15 aos 30 kg. Viçosa, MG: UFV, 1996. 150 p. Tese (Doutorado em Zootecnia) - Universidade Federal de Viçosa, 1996.
ROSTAGNO, H.S., BARBARINO JR., P., BARBOSA, W.A. Exigências nutricionais das aves determinadas no Brasil. In: SIMPÓSIO INTERNACIONAL SOBRE EXIGÊNCIAS NUTRICIONAIS DE AVES E SUÍNOS, 1996, Viçosa. Anais... Viçosa, MG: Jard, 1994. p.361-388, 1996.

SILVA, D.J. 1990. Análise de alimentos: métodos químicos e biológicos. Viçosa, MG: UFV. 166p.

SIZEMORE, F.G., SIEGEL, H.S. 1993. Growth, feed conversion, and carcass composition in females of four broiler crosses fed starter diets with different energy levels and energy to protein ratios. Poult. Sci., 72:2216-2228.

TARDIN, A.C. Conceituação e importância da energia na nutrição das aves. In: SIMPÓSIO INTERNACIONAL DE AMBIÊNCIA E INSTALAÇÃO NA AVICULTURA INDUSTRIAL, 1995, Campinas. Anais... Campinas, SP: FACTA, 1995, p.213-239.

UNIVERSIDADE FEDERAL DE VIÇOSA 1982. Manual de utilização do programa SAEG (Sistemas Para Análises Estatísticas e Genéticas). Viçosa - MG. 59p.

Recebido em: 06/11/98

Aceito em: 25/03/99 